\title{
Role of Apolipoprotein E gene polymorphism in the risk of familial hypercholesterolemia: a case-control study
}

\author{
Turky H. Almigbal1', Mohammed Ali Batais', Rana M. Hasanato², Fawaziah Khalaf Alharbi³, \\ Imran Ali Khan ${ }^{\bowtie}$, Khalid Khalaf Alharbi ${ }^{4}$
}

'Department of Family and Community Medicine, King Saud University, Riyadh, Saudi Arabia; 2Department of Pathology College of Medicine and University Hospitals, King Saud University, Riyadh, Kingdom of Saudi Arabia; ${ }^{3}$ Department of Biology Science, College of Science and Arts, Al-Qassim University, Al-Qassim, Saudi Arabia; ${ }^{4}$ Department of Clinical Laboratory Sciences, College of Applied Medical Sciences, King Saud University, PO Box-10219, Riyadh-11433, Kingdom of Saudi Arabia

\begin{abstract}
Familial Hypercholesterolemia (FH) is characterized by elevated cholesterol and based on biochemical, clinical, and genetic studies and FH disease, which was documented even with limited mutations. Earlier studies focused on Apolipoprotein E (ApoE) in variable diseases. The current study aimed to investigate the genetic association between $\mathrm{FH}$ disease and ApoE gene polymorphisms (rs429358 and rs7412) in the Saudi population. This case-control study was a hospital-based study performed in Saudi Arabia. Two hundred and four subjects in total were recruited and consisted of FH participants $(n=104)$ and the controls $(n=100)$. Common polymorphisms of ApoE gene (rs429358 and rs7412) were chosen and subjected to the genotyping using the TaqMan assay. Moreover, the ApoE risk allele E4 was proved significantly associated with $\mathrm{FH}$ cases when compared with controls (OR-2.24 (95\%Cl: 1.06-4.70); $p=0.02)$. Lipid profile parameters were significantly associated $(p<0.05)$; however, the $A p o E$ alleles and lipid profiles were not correlated $(p>0.05)$. In conclusion, the FH case-control study was associated with the E4 allele in the Saudi population. However, E4 allele was appeared as a reliable risk marker for lipid profiles, but not for ApoE alleles.
\end{abstract}

Key words: familial hypercholesterolemia, ApoE gene, TaqMan assay, Saudi population.

Received: 24 October, 2017; revised: 28 June, 2018; accepted: 02 July, 2018; available on-line: 15 September, 2018

$\triangle$ e-mail: imkhan@ksuedu.sa

Abbreviations: ApoE, Apolipoprotein E; CAD, coronary artery disease; Cl, confidence interval; CHD, coronary heart disease; CVD, cardiovascular disease; FH, Familial Hypercholesterolemia; HDL-C, high density lipoprotein cholesterol; HWE, Hardy-Weinberg equilibrium; LDL-C, low density lipoprotein cholesterol; TG, triglycerides; TC, total cholesterol VLDL, very low density lipoproteins; WES, whole-exome sequencing

\section{INTRODUION}

Familial Hypercholesterolemia (FH-OMIM\#143890) is an autosomal dominant pattern of limited genetic complexity, along with premature atherosclerotic cardiovascular disease (CVD) (Chan et al., 2016; Paquette et al., 2018). The single pathogenic variant involved is related to LDLR (60-80\%), APOB (1-5\%), or PCSK9 gene (upto $3 \%$ ), affecting one in three people (Maurera et al., 2016). Recent studies confirmed that the FH prevalence was not 1:500 but 1:250 (van Lennep, 2016). It causes high LDL-R level from birth, due to a family history of high cholesterol (Onorato \& Sturm, 2016). FH was diagnosed for the first time 50 years ago, and gained attention due to its connection to atherosclerosis and coronary heart disease (CHD). The association between genetic polymorphisms and clinical diseases was recognized earlier. Functional mutational studies from the earlier reports in specific genes (LDLR, APOB, PCSK9, and LDLRAP1) proved useful in FH diagnosis (Radovica-Spalvina et al., 2015). Due to smoking FH patients, with high triglycerides (TG) level and low blood pressure within the recommended limits (Pajak et al., 2016). Molecular diagnostic techniques revealed the relation between $\mathrm{FH}$ and Apolipoprotein $\mathrm{E}$ (ApoE) gene (Awan et al., 2013; Carmena et al., 1993; Eto et al., 1996; Jensen, 2002; Utermann et al., 1979). The ApoE gene was recognized as a genetic marker for coronary artery disease (CAD). The function of ApoE in lipid metabolism with serum glycoprotein serves as a ligand for cell-surface receptors and very low density lipoproteins (VLDL) in the liver and in the control's intestinal cholesterol absorption (Karahan et al., 2015; Yousuf \& Iqbal, 2015). The ApoE gene was extensively studied in several diseases and it plays an important role in lipid metabolism (Megale et al., 2016). The ApoE allele e4 increases LDL-C levels and decreases ApoE plasma concentrations (Davignon et al., 1988). Three variable alleles (E2, E3 and E4) account for $A$ poE polymorphism that produces 6 genotypes: E2/ $\mathrm{E} 2, \mathrm{E} 3 / \mathrm{E} 3$, and E4/E4, which are homozygous, and $\mathrm{E} 2 / \mathrm{E} 3, \mathrm{E} 2 / \mathrm{E} 4$, and $\mathrm{E} 3 / \mathrm{E} 4$, which are heterozygous (Afroze et al., 2016). These alleles are associated with rs429358 (Arg-130-Cyt) and rs7412 (Cys-163-Arg) polymorphisms that appear in the coding region of missense mutations of the ApoE gene. The combinations of these SNPs alleles results in the production of the following transcripts: Arg/Cys (referred to as isoform e3), Arg/ Arg (isoform e4), Cys/Cys (isoform e2), and Cys/Arg (a rare isoform, seldom observed) (Alharbi et al., 2014). The studies on FH in relation to the genetic polymorphisms are limited and up to now no genetic study examined the FH in Saudi Arabia. Thus, the aim of the present research was to investigate the genetic association between FH cases and the ApoE gene polymorphisms (rs429358 and rs7412) in the Saudi population.

\section{MATERIALS AND METHODS}

Subjects. This case-control study was performed at King Khalid University Hospital (KKUH), Riyadh, a major city in Saudi Arabia. There were 104 FH cases recruited based on the diagnosis using the Dutch group 
Table 1. Baseline characteristics of FH cases and controls.

\begin{tabular}{|c|c|c|c|c|}
\hline S. No & & $\begin{array}{l}\text { FH cases } \\
(n=104)\end{array}$ & $\begin{array}{l}\text { Healthy controls } \\
(n=100)\end{array}$ & $p$ value \\
\hline 1 & Age (years) & $57.76 \pm 9.94$ & $44.02 \pm 6.29$ & $p=0.0001$ \\
\hline 2 & Gender: Male/Female & $74(71.2 \%): 30(28.8 \%)$ & $40(40 \%): 60(60 \%)$ & $p=0.62$ \\
\hline 3 & Height (kg) & $165.7 \pm 7.53$ & NA & NA \\
\hline 4 & Weight (cms) & $74.1 \pm 9.40$ & NA & NA \\
\hline 5 & BMI $\left(\mathrm{kg} / \mathrm{m}^{2}\right)$ & $27.1 \pm 1.91$ & NA & NA \\
\hline 6 & $\mathrm{TG}(\mathrm{mmol} / \mathrm{L})$ & $1.36 \pm 0.50$ & $1.6 \pm 0.99$ & $p=0.009$ \\
\hline 7 & $\mathrm{TC}(\mathrm{mmol} / \mathrm{L})$ & $6.27 \pm 0.42$ & $4.8 \pm 0.73$ & $p=0.003$ \\
\hline 8 & $\mathrm{HDL}-\mathrm{C}(\mathrm{mmol} / \mathrm{L})$ & $1.39 \pm 0.46$ & $0.6 \pm 0.27$ & $p=0.71$ \\
\hline 9 & $\mathrm{LDL}-\mathrm{C}(\mathrm{mmol} / \mathrm{L})$ & $4.42 \pm 0.57$ & $3.7 \pm 0.72$ & $p=0.003$ \\
\hline
\end{tabular}

FH, Familial hypercholesterolemia; TG, Triglycerides; TC, Total cholesterol; HDL-C, high density lipoprotein cholesterol; LDL-C, low density lipoprotein cholesterol; NA, Not analysed.

classification criteria (Lye et al., 2013). Ethical approval for this study was obtained from the Institutional Review Board at King Saud University (E-2-829). Selection of the 100 control subjects was described previously (Alharbi et al., 2015).

Blood analysis. Each patient provided $5 \mathrm{ml}$ of blood for biochemical and molecular analysis. A serum sample of $3 \mathrm{ml}$ was used for the biochemical assays and $2 \mathrm{ml}$ of the EDTA sample was used for the molecular analysis. The serum sample was used to obtain the lipid profile comprising of total cholesterol (TC), TG, high density lipoprotein-cholesterol (HDL-C) and low density lipoprotein-cholesterol (LDL-C). The assessment of the lipid profile was described in the earlier publication (Alharbi et al., 2013). DNA from peripheral leukocytes was isolated using Norgen DNA extraction kit (Thorold, Ontario, Canada). NanoDrop (Fisher Scientific, Waltham, MA, USA) was used to assess the quality of genomic DNA spectrophotometrically. TaqMan (Fisher Scientific, Waltham, MA, USA) assay genotyping as described (Alharbi et al., 2014).

Statistical analysis. The variables were compared between FH cases and healthy controls using the Student' $t$-test. Anthropometric and lipid profile data were presented as mean \pm S.D. for continuous variables. Categorical variables were compared using the chi-square test and presented as percentages. Goodness of fit test was exploited to calculate the Hardy-Weinberg equilibrium (HWE) in FH cases and healthy controls. Allele frequencies were calculated with gene counting. Univariate logistic regression analysis was used to compare the genotype and allele frequencies between the cases and controls and the results were presented as odds ratio (OR) and 95\% confidence interval (CI) values. The Yates correction was also applied during the analysis of the genotyping. ANOVA was performed on the lipid profiles and allele frequencies. A $p<0.05$ was considered statistically significant. Altogether, the statistical analysis was performed using the statistical package for social sciences (SPSS-22, Chicago, IL, USA).

\section{RESULTS}

Overall, 204 subjects were included in this study, divided into $104 \mathrm{FH}$ cases and 100 controls. Table 1 presents the anthropometric and biochemical characteristics of all the study participants and the results of the t-test. The mean age of FH cases and controls was 57.76 \pm 9.94 and $44.02 \pm 6.29$ years, respectively. The BMI value of the $\mathrm{FH}$ cases equaled $27.1 \pm 1.91 \mathrm{~kg} / \mathrm{m}^{2}$. However, comparison between FH and control cases included age, TC, TG, HDL-C and LDL-C, which were positively associated with statistical significance $(p<0.05)$. Gender parameter did not show any gender association $(p=0.58)$; one of the reasons could be unequal gender proportions in the studied groups i.e., $71.2 \%$ of males in $\mathrm{FH}$ cases and only $60 \%$ in controls.

In this case-control study, two specific SNPs (rs429358 and rs7412) of the $A p o E$ gene were analyzed, in relation to them with FH in the Saudi population. HWE showed the association in the Saudi population. The genotype and allele distribution in FH cases and controls was pre-

Table 2. Genotype distribution of TaqMan and allele frequencies in FH cases and controls

\begin{tabular}{|c|c|c|c|c|c|c|}
\hline & FH cases $(n=104)$ & Controls $(n=100)$ & $x^{2}$ & OR & $95 \% \mathrm{Cl}$ & $p$ value \\
\hline E2/E2 & 01 (0.96\%) & $00^{*}(0.0 \%)$ & 0.46 & 2.91 & $0.11-72.3$ & 0.49 \\
\hline E2/E3 & $07(6.7 \%)$ & $04(4 \%)$ & 0.74 & 1.73 & $0.49-6.1$ & 0.38 \\
\hline E2/E4 & $02(1.9 \%)$ & $00 *(0.0 \%)$ & 1.27 & 4.90 & $0.23-103.4$ & 0.25 \\
\hline E3/E3 & 74 (71.2\%) & $85(85 \%)$ & 5.60 & 0.43 & $0.21-0.87$ & 0.01 \\
\hline E3/E4 & $18(17.3 \%)$ & $11(11 \%)$ & 1.65 & 1.69 & $0.76-3.79$ & 0.19 \\
\hline E4/E4 & $02(1.9 \%)$ & $00^{*}(0.0 \%)$ & 1.27 & 4.90 & $0.23-103.4$ & 0.25 \\
\hline$\varepsilon 2$ & $11(5.3 \%)$ & $04(2 \%)$ & 3.11 & 2.73 & $0.85-8.73$ & 0.07 \\
\hline$\varepsilon 3$ & $173(83.2 \%)$ & $185(92.5 \%)$ & 8.22 & 0.40 & $0.21-0.75$ & 0.004 \\
\hline$\varepsilon 4$ & 24 (11.5\%) & $11(5.5 \%)$ & 4.72 & 2.24 & $1.06-4.70$ & 0.02 \\
\hline
\end{tabular}


Table 3. Correlation between $A p o E$ alleles and the lipid profile

\begin{tabular}{lllll}
\hline & E2 & E3 & E4 & $p$ value \\
\hline TG $(\mathrm{mmol} / \mathrm{L})$ & $1.42 \pm 0.37$ & $1.37 \pm 0.50$ & $1.33 \pm 0.53$ & 0.27 \\
\hline $\mathrm{TC}(\mathrm{mmol} / \mathrm{L})$ & $6.36 \pm 0.52$ & $6.27 \pm 0.41$ & $6.22 \pm 0.42$ & 0.54 \\
\hdashline $\mathrm{HDL}-\mathrm{C}(\mathrm{mmol} / \mathrm{L})$ & $1.48 \pm 0.41$ & $1.39 \pm 0.45$ & $1.38 \pm 0.53$ & 0.50 \\
\hline $\mathrm{LDL}-\mathrm{C}(\mathrm{mmol} / \mathrm{L})$ & $4.23 \pm 0.7$ & $4.22 \pm 0.55$ & $4.20 \pm 0.61$ & 0.45 \\
\hline
\end{tabular}

sented in Table 2. The genotype frequencies in $\mathrm{FH}$ cases were as follows: E2/E2 - 0.96\%, E2/E3 - 6.7\%, E2/ $\mathrm{E} 4-1.9 \%, \mathrm{E} 3 / \mathrm{E} 3-71.2 \%, \mathrm{E} 3 / \mathrm{E} 4-17.3 \%, \mathrm{E} 4 / \mathrm{E} 4-$ $1.9 \%$ and for the controls: E2/E2 - 4\%, E3/E3 - 85\%, $\mathrm{E} 3 / \mathrm{E} 4-11 \%$. In $\mathrm{FH}$ cases, the percentage of $\varepsilon 2, \varepsilon 3$, and $\varepsilon 4$ alleles were $5.3 \%, 83.2 \%$, and $11.5 \%$, whereas in the controls it was only $2 \%, 92.5 \%$ and $5.5 \%$, respectively. In control subjects, E2/E2, E2/E4 and E4/E4 did not appear at all $(\mathrm{n}=0)$. The $\mathrm{E} 3 / \mathrm{E} 4$ genotypes was completely absent in the FH cases and controls (OR0.40; (95\% CI: 0.21-0.75) $p=0.19$ ) and E4/E4 (OR4.90; [95\% CI: 0.23-103.4) $p=0.25)$. However, the e4 allele showed a positive association (OR-2.24; (95\% CI: 1.06-4.70) $p=0.02$ ). The ANOVA on lipid profiles values (such as TC, TG, HDL-C and LDL-C) and allele frequencies did not show any association with $\mathrm{FH}(p>0.05$ respectively). The statistical test results were presented in Table 3. However, for all four lipid profile parameters the levels were higher in the e 2 allele bearers than in the case of alleles e3 and e4.

\section{DISCUSSION}

The presented study evaluated the relation between $\mathrm{FH}$ disease and the $A p o E$ gene polymorphisms in the Saudi population. It revealed a nominal association i.e., association with the e4 allele $(p=0.02)$. We did not find any genotype association, which may be due to the small sample size. Genetic susceptibility is thought to contribute to the pathogenesis of $\mathrm{FH}$ disease. However, FH prevalence in Saudi Arabia is still not well-documented, with too few studies focused on the subject (Al-Allaf et al., 2017; Al-Allaf et al., 2016; Al-Allaf et al., 2014; AlAllaf et al., 2015; Alallaf et al., 2017; Alharbi et al., 2013; Alharbi et al., 2015; Nuglozeh, 2017). Moreover, FH disease may have a high prevalence may be due to connection with obesity $(68 \%)$ and consanguineous marriages $(\sim 50-60 \%)$ in both the Saudi and Arab populations. In addition, the number of T2DM cases has been increasing (Alharbi et al., 2016), while FH disease is still underdiagnosed, but actively being evaluated. A previous study on 69016 subjects from the Danish population revealed the prevalence of $\sim 1$ in 137 for diagnosed basing on the Dutch lipid clinic criteria, suggesting that FH is possibly underdiagnosed. The FH samples selected in this study has been selected through the Dutch group criteria, as only clinicians has diagnose $\mathrm{FH}$ disease (Benn et al., 2012).

Identification of SNPs in the DNA coding regions enables a better understanding of the pathophysiology of the diseases and may result in improved diagnosis, prevention and, treatment. Approximately, $90 \%$ of DNA sequence variants in humans are localized in coding regions (Khan et al., 2016). A significant progress regarding the detection of genetic diseases was documented (Risch \& Merikangas, 1996). The techniques for sequencing of that complete exome are used to analyze the genetic variation in the affected patients with decreasing costs and increasing accuracy (Katsanis \& Katsanis, 2013). The whole-exome sequencing (WES) technique identified the disease-causing marker and is a promising tool for understanding the molecular mechanisms of the diseases and for personalized treatment (Braenne et al., 2014). Earlier studies implemented exome sequencing in 125 $\mathrm{FH}$-diagnosed patients in the UK population. The results did not reveal any novel genetic variants due to the selection of a limited number of genes. Exome sequencing analysis also failed to identify disease-related loci in both British and German population (Braenne et al., 2014; Futema et al., 2014). However, in the Saudi population, only specific genes were selected for the next-generation sequencing and a novel variant (c.2026delG, p. Gly676fs) identified in the LDLR gene in exon 14 (Al-Allaf et al., 2015). More number of studies have been published with the advanced technology in genotyping and detection of huge variant numbers in the human genome, which did not provide a better understanding of the disease mechanisms. Meta-analysis studies are defined as statistical procedures that integrates the results of several independent studies, thereby playing a central role in evidence-based medicine (Haidich, 2010; Salanti et al., 2005).

Meta-analysis of GWAS data can expand the associated data documented from earlier studies with assigned genotype data. However, the initial selection should be performed for the combinational results of GWAS and meta-analyses, along with genetic association with strong statistical support; at the same time, GWAS and metaanalyses showed convincing sizes effects are moderate in current platforms, as sample sizes can still explain the majority of large genetic risk for most common diseases (Zeggini \& Ioannidis, 2009).

Meta-analysis studies on the ApoE gene in relation to multiple diseases revealed both were positive (Arati et al., 2016; Cao et al., 2014; Garatachea et al., 2015; Gatt et al., 2015; Han et al., 2013; Li et al., 2015; Liao et al., 2014; Lin et al., 2014; Meng et al., 2013; Rubino et al., 2013; Sun et al., 2015; Wang et al., 2014; Xu et al., 2014; Yin et al., 2012; Yin et al., 2013; Yin et al., 2014; Zhang et al., 2014a; Zhang et al., 2014b; Zhang et al., 2015), and negative associations (Agarwal \& Tripathi, 2014; Gu et al., 2013; Liu et al., 2014; Miao et al., 2015; Stoumpos et al., 2013; Tian et al., 2014; Wang et al., 2013; Xu et al., 2015; Zhao et al., 2016; Zhu et al., 2016). Earlier reports in the nineties did not provide unequivocal conclusions regarding the relation of the ApoE gene and FH in different populations (Carmena et al., 1993; Friedlander \& Leitersdorf, 1996; Utermann et al., 1979). However, recently, the positive, nominal, and negative associational studies for FH were reported (Aledo et al., 2015; Angarica et al., 2016; Drogari et al., 2014; Hiddink et al., 2015; Ho et al., 2015; Leduc et al., 2016; Saavedra et al., 2014; Sanchez Munoz-Torrero et al., 2014; Versmissen et al., 2015). The initial study on Saudi FH subjects and the ApoE gene correlated the risk with the $\mathrm{E} 4$ allele, which may be due to the low sample size. The E4 risk allele of ApoE gene was proved to be associated with TC (Fallaize et al., 2016). However, different studies based on NGS and exome sequencing did not show the diagnostic bio-marker with ApoE or other genes/SNPs (Al-Allaf et al., 2015; Angarica et al., 2016; Graham et al., 2017; Hinchcliffe et al., 2014; Nikkola et al., 2017; Radovica-Spalvina et al., 2015; Tada et al., 2016; Vandrovcova et al., 2013). The current study had specific limitations such as unequal genders proportion, low sample size, missing clinical data and family history. 
However, the TaqMan assay genotyping performed in this study enable by passing the negative analysis and increased accuracy of the results.

Our results showed that the $\_4$ allele is associated with $\mathrm{FH}$ cases in the Saudi population. The $\varepsilon 4$ allele proved an important and reliable marker and did not appear to have a significant association with lipid profiles. Future studies on FH should be implemented with large sample sizes, comprised of global ethnicities and confirm the relation between the FH and ApoE gene. Exome- and next-generation sequencing analysis should be performed to identify a reliable diagnostic marker linking FH disease with specific SNP/variations.

\section{Conflict of Interest}

All the authors declare no conflict of interest in relation to this manuscript.

\section{Acknowledgements of Financial Support}

This project was supported by the College of Medicine Research Centre, Deanship of Scientific Research, King Saud University, Riyadh, Saudi Arabia.

\section{REFERENCES}

Afroze D, Yousuf A, Tramboo NA, Shah ZA, Ahmad A (2016) ApoE gene polymorphism and its relationship with coronary artery disease in ethnic Kashmiri population. Clinical and experimental medicine 16: 551-556. doi: 10.1007/s10238-015-0389-7

Agarwal R, Tripathi CB (2014) Association of apolipoprotein E genetic variation in Alzheimer's disease in Indian population: a metaanalysis. Am J Alzheimer's Disease Other Dementias 29: 575-582. doi: $10.1177 / 1533317514531443$

Alallaf F, FA HN, Alnefaie M, Almaymuni A, Rashidi OM, Alhabib K, Alnouri F, Alama MN, Athar M, Awan Z (2017) The spectrum of familial hypercholesterolemia $(\mathrm{FH})$ in Saudi Arabia: prime time for patient FH registry. Open Cardiovascular Med J 11: 66-75. doi: 10.2174/1874192401711010066

Al-Allaf FA, Alashwal A, Abduljaleel Z, Taher MM, Bouazzaoui A, Abalkhail H, Al-Allaf AF, Athar M (2017) Compound heterozygous LDLR variant in severely affected familial hypercholesterolemia patient. Acta Biochim Pol 64: 75-79. doi: 10.18388/abp.2016_1283

Al-Allaf FA, Alashwal A, Abduljaleel Z, Taher MM, Siddiqui SS, Bouazzaoui A, Abalkhail H, Aun R, Al-Allaf AF, AbuMansour I, Azhar Z, Ba-Hammam FA, Khan W, Athar M (2016) Identification of a recurrent frameshift mutation at the LDLR exon 14 (c.2027delG, p.(G676Afs*33)) causing familial hypercholesterolemia in Saudi Arab homozygous children. Genomics 107: 24-32. doi: 10.1016/j.ygeno.2015.12.001

Al-Allaf FA, Athar M, Abduljaleel Z, Bouazzaoui A, Taher MM, Own R, Al-Allaf AF, AbuMansour I, Azhar Z, Ba-Hammam FA, Abalkhail H, Alashwal A (2014) Identification of a novel nonsense variant c.1332dup, p.(D445*) in the LDLR gene that causes familial hypercholesterolemia. Human Genome Variation 1: 14021. doi: 10.1038/hgv.2014.21

Al-Allaf FA, Athar M, Abduljaleel Z, Taher MM, Khan W, Ba-Hammam FA, Abalkhail H, Alashwal A (2015) Next generation sequencing to identify novel genetic variants causative of autosomal dominant familial hypercholesterolemia associated with increased risk of coronary heart disease. Gene 565: 76-84. doi: 10.1016/j. gene.2015.03.064

Aledo R, Padro T, Mata P, Alonso R, Badimon L (2015) rs11613352 polymorphism (TT genotype) associates with a decrease of triglycerides and an increase of HDL in familial hypercholesterolemia patients. Revista Espanola de Cardiologia (English edn) 68: 305-309. doi: 10.1016/j.rec.2014.04.015

Alharbi KK, Alharbi FK, Alharbi FK, Ghneim HK, Al-Sulaiman A, Alodhayani AA, Tabassum SN, Khan IA (2016) Amendment of amino acid in Q192R genetic polymorphism of paraoxonase 1 is a conventional risk factor for type 2 diabetes mellitus in the Saudi population. Int J Clin Exp Med 9: 16605-16612

Alharbi KK, Kashour TS, Al-Hussaini W, Al-Nbaheen MS, Mohamed S, Hasanato RM, Tamimi W, Al-Naami MY, Khan IA (2013) Association of angiotensin converting enzyme gene insertion/deletion polymorphism and familial hypercholesterolemia in the Saudi population. Lipids Health Dis 12: 177. doi: 10.1186/1476-511x-12-177

Alharbi KK, Kashour TS, Al-Hussaini W, Nbaheen MS, Hasanato RM, Mohamed S, Tamimi W, Khan IA (2015) Screening for genetic mu- tations in LDLR gene with familial hypercholesterolemia patients in the Saudi population. Acta Biochim Pol 62: 559-562. doi: 10.18388/ abp.2015_1015

Alharbi KK, Khan IA, Syed R (2014) Association of apolipoprotein E polymorphism with type 2 diabetes mellitus in a Saudi population. DNA Cell Biol 33: 637-641. doi: 10.1089/dna.2014.2461

Angarica VE, Orozco M, Sancho J (2016) Exploring the complete mutational space of the LDL receptor LA5 domain using molecular dynamics: linking SNPs with disease phenotypes in familial hypercholesterolemia. Human Mol Genet 25: 1233-1246. doi: 10.1093/ hmg/ddw004

Arati S, Sibin MK, Bhat DI, Narasingarao KV, Chetan GK (2016) Polymorphisms of apolipoprotein $\mathrm{E}$ and aneurysmal subarachnoid haemorrhage: A meta-analysis. Meta Gene 9: 151-158. doi: 10.1016/j. mgene.2016.06.003

Awan Z, Choi HY, Stitziel N, Ruel I, Bamimore MA, Husa R, Gagnon MH, Wang RH, Peloso GM, Hegele RA, Seidah NG, Kathiresan S, Genest J (2013) APOE p.Leu167del mutation in familial hypercholesterolemia. Atherosclerosis 231: 218-222. doi: 10.1016/j.atherosclerosis.2013.09.007

Benn M, Watts GF, Tybjaerg-Hansen A, Nordestgaard BG (2012) Familial hypercholesterolemia in the danish general population: prevalence, coronary artery disease, and cholesterol-lowering medication. J Clin Endocrinol Metabolism 97: 3956-3964. doi: 10.1210/jc.20121563

Braenne I, Reiz B, Medack A, Kleinecke M, Fischer M, Tuna S, Hengstenberg C, Deloukas P, Erdmann J, Schunkert H (2014) Wholeexome sequencing in an extended family with myocardial infarction unmasks familial hypercholesterolemia, BMC Cardiovascular Disorders 14: 108. doi: 10.1186/1471-2261-14-108

Cao L, Wang K, Gu T, Du B, Song J (2014) Association between APOE epsilon 4 allele and postoperative cognitive dysfunction: a meta-analysis. Int J Neuroscience 124: 478-485

Carmena R, Roederer G, Mailloux H, Lussier-Cacan S, Davignon J (1993) The response to lovastatin treatment in patients with heterozygous familial hypercholesterolemia is modulated by apolipoprotein E polymorphism. Metabolism: Clin Exp 42: 895-901

Chan DC, Pang J, Barrett PHR, Sullivan DR, Burnett JR, van Bockxmeer FM, Watts GF (2016) $\omega-3$ Fatty acid ethyl esters diminish postprandial lipemia in familial hypercholesterolemia. J Clin Endocrinol Metabolism 101: 3732-3739

Davignon J, Bouthillier D, Nestruck AC, Sing CF (1988) Apolipoprotein $\mathrm{E}$ polymorphism and atherosclerosis: insight from a study in octogenarians. Transactions Am Clin Climatological Ass 99: 100-110

Drogari E, Ragia G, Mollaki V, Elens L, Van Schaik RH, Manolopoulos VG (2014) POR*28 SNP is associated with lipid response to atorvastatin in children and adolescents with familial hypercholesterolemia. Pharmacogenomics 15: 1963-1972. doi: 10.2217/pgs.14.138

Eto M, Watanabe K, Chonan N, Ishii K (1988) Familial hypercholesterolemia and apolipoprotein E4. Atherosclerosis 72: 123-128

Fallaize R, Celis-Morales C, Macready AL, Marsaux CF, Forster H, O’Donovan C, Woolhead C, San-Cristobal R, Kolossa S, Hallmann J, Mavrogianni C, Surwillo A, Livingstone KM, Moschonis G, Navas-Carretero S, Walsh MC, Gibney ER, Brennan L, Bouwman J, Grimaldi K, Manios Y, Traczyk I, Drevon CA, Martinez JA, Daniel H, Saris WH, Gibney MJ, Mathers JC, Lovegrove JA (2016) The effect of the apolipoprotein $\mathrm{E}$ genotype on response to personalized dietary advice intervention: findings from the Food4Me randomized controlled trial. Am J Clin Nutrition 104: 827-836. doi: 10.3945/ ajen.116.135012

Friedlander Y, Leitersdorf E (1996) Influence of apolipoprotein E genotypes on plasma lipid and lipoprotein concentrations: results from a segregation analysis in pedigrees with molecularly defined familial hypercholesterolemia. Genetic Epidemiol 13: 159-177. doi: 10.1002/ (SICI)1098-2272(1996)13:2\&lt;159::AID-GEPI3\&gt;3.0.CO;2-3

Futema M, Plagnol V, Li K, Whittall RA, Neil HA, Seed M, Bertolini S, Calandra S, Descamps OS, Graham CA, Hegele RA, Karpe F, Durst R, Leitersdorf E, Lench N, Nair DR, Soran H, Van Bockxmeer FM, Humphries SE (2014) Whole exome sequencing of familial hypercholesterolaemia patients negative for LDLR/APOB/ PCSK9 mutations. J Med Genet 51: 537-544. doi: 10.1136/jmedgenet-2014-102405

Garatachea N, Marin PJ, Santos-Lozano A, Sanchis-Gomar F, Emanuele E, Lucia A (2015) The ApoE gene is related with exceptional longevity: a systematic review and meta-analysis. Rejuvenation Res 18: 3-13. doi: $10.1089 /$ rej.2014.1605

Gatt JM, Burton KL, Williams LM, Schofield PR (2015) Specific and common genes implicated across major mental disorders: a review of meta-analysis studies. I Psychiatric Res 60: 1-13. doi: 10.1016/j. jpsychires.2014.09.014

Graham CA, Latten MJ, Hart PJ (2017) Molecular diagnosis of familial hypercholesterolaemia. Curr Opin Lipidology 28: 313-320. doi: 10.1097/mol.0000000000000430

Gu L, Su L, Chen Q, Liang B, Qin Y, Xie J, Wu G, Yan Y, Long J, Wu H, Tan J, Dou W, Chen W, Wu P, Wang J (2013) Association between the apolipoprotein $\mathrm{E}$ gene polymorphism and ischemic 
stroke in Chinese populations: New data and meta-analysis. Experimental Therapeutic Med 5: 853-859. doi: 10.3892/etm.2012.866

Haidich A-B (2010) Meta-analysis in medical research. Hippokratia 14: 29

Han Y, Liu T, Lu L (2013) Apolipoprotein E gene polymorphism in psoriasis: a meta-analysis. Archives $M e d$ Res 44: 46-53

Hiddink L, Dallinga-Thie GM, Hovingh GK, de Visser MC, Peer PG, Stalenhoef AF, van Heerde WL (2015) Annexin A5 haplotypes in familial hypercholesterolemia: lack of association with carotid intima-media thickness and cardiovascular disease risk. Atherosclerosis 238: 195-200. doi: 10.1016/j.atherosclerosis.2014.11.023

Hinchcliffe M, Le H, Fimmel A, Molloy L, Freeman L, Sullivan D, Trent RJ (2014) Diagnostic validation of a familial hypercholesterolaemia cohort provides a model for using targeted next generation DNA sequencing in the clinical setting. Pathology 46: 60-68. doi: $10.1097 /$ pat.0000000000000026

Ho CK, Musa FR, Bell C, Walker SW (2015) LDLR gene synonymous mutation c.1813C $>\mathrm{T}$ results in mRNA splicing variation in a kindred with familial hypercholesterolaemia. Ann Clin Biochem 52: 680-684. doi: 10.1177/0004563215572702

Jensen HK (2002) The molecular genetic basis and diagnosis of familial hypercholesterolemia in Denmark. Danish Medical Bulletin 49: 318-3145

Karahan Z, Ugurlu M, Ucaman B, Ulug AV, Kaya I, Cevik K, Ozturk O, Iyem H (2015) Relation between apolipoprotein e gene polymorphism and severity of coronary artery disease in acute myocardial infarction. Cardiology Res Practice 2015: 363458. doi: $10.1155 / 2015 / 363458$

Katsanis SH, Katsanis N (2013) Molecular genetic testing and the future of clinical genomics. Nat Rev Genet 14: 415-426. doi: 10.1038/ nrg3493

Khan IA, Vattam KK, Jahan P, Hasan Q, Rao P (2016) Importance of glucokinase $-258 \mathrm{G} / \mathrm{A}$ polymorphism in Asian Indians with posttransplant and type 2 diabetes mellitus. Intractable Rare Dis Res $\mathbf{5}$ 25-30. doi: 10.5582/irdr.2015.01040

Leduc V, Bourque L, Poirier J, Dufour R (2016) Role of rs3846662 and HMGCR alternative splicing in statin efficacy and baseline lipid levels in familial hypercholesterolemia. Pharmacogenet Genomics 26 1-11. doi: 10.1097/fpc.0000000000000178

Li T, Shi Y, Yin J, Qin Q, Wei S, Nie S, Liu L (2015) The association between lipid metabolism gene polymorphisms and nephropathy in type 2 diabetes: a meta-analysis. Int Urology Nephrology 47: 117-130

Liao R, Ye M, Xu X (2014) An updated meta-analysis: apolipoprotein $\mathrm{E}$ genotypes and risk of primary open-angle glaucoma. Mol Vis 20: 1025-1036

Lin YJ, Pan JL, Jiang MJ, Tan JH, Zhong W, Gong TK, Jin XC, Cai SH, Wu YJ (2014) Apo E gene polymorphism affects development of type 2 diabetic nephropathy in Asian populations, especially in East Asians: an updated meta-analysis. Med Sci Monitor: Int Med I Exp Clin Res 20: 1596-1603. doi: 10.12659/msm.892111

Liu M, Bian C, Zhang J, Wen F (2014) Apolipoprotein E gene polymorphism and Alzheimer's disease in Chinese population: a metaanalysis. Scientific Reports 4: 4383. doi: 10.1038/srep04383

Lye SH, Chahil JK, Bagali P, Alex L, Vadivelu J, Ahmad WA, Chan SP, Thong MK, Zain SM, Mohamed R (2013) Genetic polymorphisms in LDLR, APOB, PCSK9 and other lipid related genes associated with familial hypercholesterolemia in Malaysia. PLoS One 8: e60729. doi: 10.1371/journal.pone.0060729

Maurera F, Pradervandb S, Guilleretb I, Nanchend D, Maghraouib A, Chapatteb L, Bojkowskac K, Bhuiyana ZA, Jacquemontb N, Harshmanc K (2016) Identification and molecular characterisation of Lausanne Institutional Biobank participants with familial hypercholesterolaemia - a proof-of-concept study. Swiss Med Wkly 146: w14326

Megale RZ, de Loyola Filho AI, Firmo JO, Lima-Costa MF, Peixoto SV (2016) Apolipoprotein E polymorphism and functional disability in Brazilian elders: the Bambui health and aging study. Cadernos de Saude Publica 32: e00080115. doi: 10.1590/0102-311x00080115

Meng H-x, Qi M-g, Yi Y-y, Liu Y-p (2013) Association between apolipoprotein $\mathrm{E}$ gene polymorphism and the risk of recurrent pregnancy loss: a meta-analysis. J Assisted Reproduction Genet 30: 1547-1552

Miao J, Wang F, Zheng W, Zhuang X (2015) Association of the apolipoprotein $\mathrm{E}$ polymorphism with migraine: a meta-analysis. $B M C$ Neurology 15: 138. doi: 10.1186/s12883-015-0385-2

Nikkola E, Ko A, Alvarez M, Cantor RM, Garske K, Kim E, Gee S, Rodriguez A, Muxel R, Matikainen N, Soderlund S, Motazacker MM, Boren J, Lamina C, Kronenberg F, Schneider WJ, Palotie A, Laakso M, Taskinen MR, Pajukanta P (2017) Family-specific aggregation of lipid GWAS variants confers the susceptibility to familial hypercholesterolemia in a large Austrian family. Atherosclerosis 264: 58-66. doi: 10.1016/j.atherosclerosis.2017.07.024

Nuglozeh E (2017) Whole-exomes sequencing delineates gene variants profile in a young Saudi male with familial hypercholesterolemia: case report. J Clini Diagnostic Res: JCDR 11: Gd01-GD06. doi: $10.7860 /$ jcdr/2017/28156.10143
Onorato A, Sturm AC (2016) Heterozygous familial hypercholesterolemia. Circulation 133: e587-e589

Pajak A, Szafraniec K, Polak M, Drygas W, Piotrowski W, Zdrojewski T, Jankowski P (2016) Prevalence of familial hypercholesterolemia: a meta-analysis of six large, observational, population-based studies in Poland. Arch Med Sci: AMS 12: 687

Paquette M, Dufour R, Baass A (2018) PHACTR1 genotype predicts coronary artery disease in patients with familial hypercholesterolemia. J Clin Lipidol. doi: 10.1016/j.jacl.2018.04.012

Radovica-Spalvina I, Latkovskis G, Silamikelis I, Fridmanis D, Elbere I, Ventins K, Ozola G, Erglis A, Klovins J (2015) Next-generationsequencing-based identification of familial hypercholesterolemia-related mutations in subjects with increased LDL-C levels in a latvian population. BMC Med Genet 16: 86. doi: 10.1186/s12881-015-0230-x

Risch N, Merikangas K (1996) The future of genetic studies of complex human diseases. Science 273: 1516-1517

Rubino E, Vacca A, Govone F, De Martino P, Pinessi L, Rainero I (2013) Apolipoprotein E polymorphisms in frontotemporal lobar degeneration: a meta-analysis. Alsheimer's Dementia 9: 706-713

Saavedra YG, Dufour R, Davignon J, Baass A (2014) PCSK9 R46L, lower LDL, and cardiovascular disease risk in familial hypercholesterolemia: a cross-sectional cohort study. Arteriosclerosis, Thrombosis, Vascular Biol 34: 2700-2705. doi: 10.1161/atvbaha.114.304406

Salanti G, Sanderson S, Higgins JP (2005) Obstacles and opportunities in meta-analysis of genetic association studies. Genetics Med: Official J Am College Med Genet 7: 13-20. doi: 10.109701. gim.0000151839.12032.1a

Sanchez Munoz-Torrero JF, Rivas MD, Zamorano J, Alonso R, JoyaVazquez P, Padro T, Mata P (2014) rs1801275 Interleukin-4 receptor alpha polymorphism in familial hypercholesterolemia. J Clin Lipidol 8: 418-422. doi: 10.1016/j.jacl.2014.04.003

Stoumpos S, Hamodrakas SJ, Anthopoulos PG, Bagos PG (2013) The association between apolipoprotein $\mathrm{E}$ gene polymorphisms and essential hypertension: a meta-analysis of 45 studies including 13, 940 cases and 16, 364 controls. I Hum Hypertension 27: 245-255. doi: $10.1038 /$ ihh. 2012.37

Sun J-H, Tan L, Wang H-F, Tan M-S, Tan L, Li J-Q, Xu W, Zhu X-C, Jiang T, Yu J-T (2015) Genetics of vascular dementia: systematic review and meta-analysis. I Alyheimer's Disease 46: 611-629

Tada H, Kawashiri MA, Okada H, Endo S, Toyoshima Y, Konno T, Nohara A, Inazu A, Takao A, Mabuchi H, Yamagishi M, Hayashi $\mathrm{K}$ (2016) A rare coincidence of sitosterolemia and familial mediterranean fever identified by whole exome sequencing. I Atherosclerosis Thrombosis 23: 884-890. doi: 10.5551/jat.34827

Tian Y, Wang J, Ye Y, Sun L, Fan Y, Wang L, Li J, Wang Z, Wang K (2014) Apolipoprotein E polymorphism and colorectal neoplasm: results from a meta-analysis. PLoS One 9: e102477. doi: 10.1371/ journal.pone.0102477

Utermann G, Vogelberg KH, Steinmetz A, Schoenborn W, Pruin N, Jaeschke M, Hees M, Canzler H (1979) Polymorphism of apolipoprotein E. II. Genetics of hyperlipoproteinemia type III. Clin Genet 15: $37-62$

van Lennep JER (2016) Knowledge equals health; why all healthcare professionals should know about familial hypercholesterolemia. Atherosclerosis 252: 188-189

Vandrovcova J, Thomas ER, Atanur SS, Norsworthy PJ, Neuwirth C, Tan Y, Kasperaviciute D, Biggs J, Game L, Mueller M, Soutar AK, Aitman TJ (2013) The use of next-generation sequencing in clinical diagnosis of familial hypercholesterolemia. Genet Med: Official J Am College Med Genet 15: 948-957. doi: 10.1038/gim.2013.55

Versmissen J, Oosterveer DM, Yazdanpanah M, Dehghan A, Holm H, Erdman J, Aulchenko YS, Thorleifsson G, Schunkert H, Huijgen R, Vongpromek R, Uitterlinden AG, Defesche JC, van Duijn CM, Mulder M, Dadd T, Karlsson HD, Ordovas J, Kindt I, Jarman A, Hofman A, van Vark-van der Zee L, Blommesteijn-Touw AC, Kwekkeboom J, Liem AH, van der Ouderaa FJ, Calandra S, Bertolini S, Averna M, Langslet G, Ose L, Ros E, Almagro F, de Leeuw PW, Civeira F, Masana L, Pinto X, Simoons ML, Schinkel AF, Green MR, Zwinderman AH, Johnson KJ, Schaefer A, Neil A, Witteman JC, Humphries SE, Kastelein JJ, Sijbrands EJ (2015) Identifying genetic risk variants for coronary heart disease in familial hypercholesterolemia: an extreme genetics approach. Eur J Human Genet: EJHG 23: 381-387. doi: 10.1038/ejhg.2014.101

Wang W, Zhou M, Huang W, Chen S, Zhang X (2013) Lack of association of apolipoprotein $\mathrm{E}$ (Apo E) epsilon2/epsilon3/epsilon4 polymorphisms with primary open-angle glaucoma: a meta-analysis from 1916 cases and 1756 controls. PLoS One 8: e72644. doi: 10.1371/ journal.pone.0072644

Wang Y, Zhou Y-F, Zhao B-Y, Gu Z-Y, Li S-L (2014) Apolipoprotein $E$ gene $\varepsilon 4 \varepsilon 4$ is associated with elevated risk of primary open angle glaucoma in Asians: a meta-analysis. BMC Med Genet 15: 60

Xu H, Li H, Liu J, Zhu D, Wang Z, Chen A, Zhao Q (2014) Metaanalysis of apolipoprotein $\mathrm{E}$ gene polymorphism and susceptibility of myocardial infarction. PLoS One 9: e104608. doi: 10.1371/journal.pone. 0104608 
Xu H, Qian Y, Guan J, Yi H, Yin S (2015) No association between the ApoE epsilon2 and epsilon4 alleles and the risk of obstructive sleep apnea: A systematic review and meta-analysis. Biomedical Rep 3: 313-318. doi: 10.3892/br.2015.425

Yin Y-W, Qiao L, Sun Q-Q, Hu A-M, Liu H-L, Wang Q, Hou Z-Z (2014) Influence of apolipoprotein E gene polymorphism on development of type 2 diabetes mellitus in Chinese Han population: a meta-analysis of 29 studies. Metabolism: Clin Exp 63: 532-541

Yin Y-W, Sun Q-Q, Zhang B-B, Hu A-M, Liu H-L, Wang Q, Hou Z-Z (2013) Association between apolipoprotein E gene polymorphism and the risk of coronary artery disease in Chinese population: evidence from a meta-analysis of 40 studies. PLoS One 8: e66924

Yin Y-W, Zhang Y-D, Wang J-Z, Li B-H, Yang Q-W, Fang C-Q, Gao C-Y, Li J-C, Zhang L-L (2012) Association between apolipoprotein $\mathrm{E}$ gene polymorphism and the risk of multiple sclerosis: a metaanalysis of 6977 subjects. Gene 511: 12-17

Yousuf FA, Iqbal MP (2015) Review: Apolipoprotein E (Apo E) gene polymorphism and coronary heart disease in Asian populations. $\mathrm{Pa}$ kistan J Pharmaceutical Sci 28: 1439-1444

Zeggini E, Ioannidis JP (2009) Meta-analysis in genomewide association studies. Pharmacogenomics 10: 191-201. doi: $10.2217 / 14622416.10 .2 .191$
Zhang C, Li S, Zhang X, Liu H, Luo Y (2015) Association of ApoE gene with type 2 diabetic nephropathy in a Chinese population: a meta-analysis of case-control studies. Annales d'Endocrinologie 76: 601-613. doi: 10.1016/j.ando.2014.12.001

Zhang M-d, Gu W, Qiao S-b, Zhu E-j, Zhao Q-m, Lv S-z (2014) Apolipoprotein $\mathrm{E}$ gene polymorphism and risk for coronary heart disease in the Chinese population: a meta-analysis of 61 studies including 6634 cases and 6393 controls. PLoS One 9: e95463

Zhang R, Wang X, Tang Z, Liu J, Yang S, Zhang Y, Wei Y, Luo W, Wang J, Li J (2014) Apolipoprotein E gene polymorphism and the risk of intracerebral hemorrhage: a meta-analysis of epidemiologic studies. Lipids Health Dis 13: 47

Zhao D, Zhang Z, Wu GB, Wang HY, Gao F, Duan XD, Lu YY, Wang ZM, You DP, Qu Y, Song J (2016) Apolipoprotein E gene polymorphism and the risk of subarachnoid hemorrhage: a metaanalysis of case-control studies. Acta Neurochirurgica 158: 1515-1522. doi: 10.1007/s00701-016-2824-2

Zhu H, Xue H, Wang H, Ma Y, Liu J, Chen Y (2016) The association of apolipoprotein E (APOE) gene polymorphisms with atherosclerosis susceptibility: a meta-analysis. Minerva Cardioangiologica 64: 47-54 